\title{
Los futuros de \\ Fernando Pessoa: \\ el poeta y sus \\ heterónimos
}

Douglas Rubio Bautista

Universidad Peruana de Ciencias Aplicadas

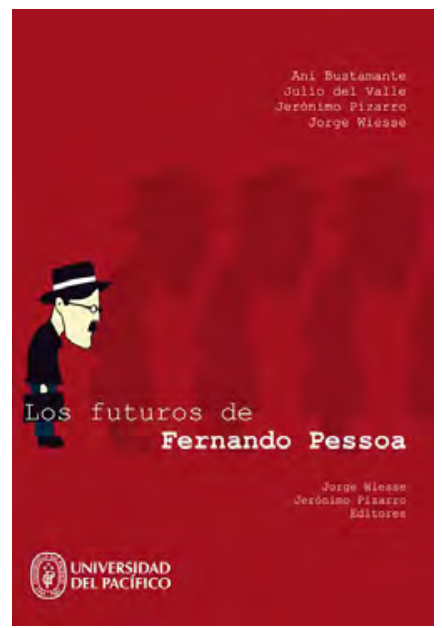

Los futuros de Fernando Pessoa

Jorge Wiesse y Jerónimo Pizarro, editores

Lima: Universidad del Pacífico

Año: 2013; 112 pp.

ISBN: 978-9972-57-265-4

Cas ponencias que participaron del conversatorio de ensayos recupera en artículos, ya de manera extendida y mejor sintetizada, Pacífico en el 2011 con el título general de Los futuros de Fernando Pessoa. Bajo la edición de Jorge Wiesse y de Jerónimo Pizarro, Los futuros de Fernando Pessoa (Lima, Universidad del Pacífico, 2013), reúne a diversos estudiosos, locales y extranjeros, de la obra poética del enigmático escritor portugués. Sin embargo, es importante el necesario matiz de esta publicación, pues es un texto que presenta una doble propuesta que se instala a partir de la publicación, como dijéramos, de los artículos originados desde las ponencias sobre este conversatorio. Además, presenta una cuidada selección de textos de Pessoa a manera de 
antología mínima, en el que se hallan algunos poemas de 35 sonetos (e ilustraciones de los originales de este poemario escrito en estilo clásico inglés), Todos los sueños del mundo cuya ortonomia es atribuida al mismo Pessoa- y fragmentos del Libro del desasosiego, de Bernardo Soares, heterónimo de Pessoa.

En líneas generales, delimitando el carácter de las diversas interpretaciones, este libro de ensayos posee tres vertientes de aproximación a Pessoa y que, en buena cuenta, develan la presencia polivante de sus versos, pues es abordado desde disciplinas próximas como la psicología y la filosofía, así como desde la literatura y la lingüística, cuyo valor se extiende en las labores de traducción de sus poemas al castellano. Así, la doctora en psicoanálisis, Ani Bustamante; el poeta y filósofo Julio del Valle; el literato y traductor Jorge Wiesse, así como el lingüista Jerónimo Pizarro son reunidos en esta publicación para delimitar sus investigaciones sobre el objetivo de un pensar en Pessoa y la proyección futura del poeta portugués a través de sus temas y textos reconocidos, y así, de manera transversal, conocer el espíritu y el pensamiento del Occidente del siglo xx en la lectura de su discurso poético.

Muchas de las claves de lectura sobre Pessoa se hallan en el primer artículo del libro, «Obras ortónimas y heterónimas de Fernando Pessoa: genealogía de una distinción», en la que Jerónimo Pizarro clasifica ambos vocablos como centrales para entender la poesía de Pessoa y ese enigma que ha representado su figura en la literatura europea. Así, como es sabido, Pessoa tenía varias "personalidades literarias» a lo largo de su producción poética. «Personalidades» o rostros poéticos a quienes Pessoa los bautizaría con los nombres de Álvaro de Campos, Alberto Caeiro y Ricardo Reis. A estos, los otros o «futuros» del poeta, se les denominaría, en líneas muy generales, sus heterónimos, una actitud que, según Pizarro, representaría un «salir de sí mismo» por parte del sujeto Pessoa, una postura que linda con lo esquizofrénico, y que, desde el análisis de Pizarro, no se entiende como una desviación psíquica de la personalidad, sino, sobre todo, como una técnica o método de composición artística, un recurso literario por parte de Pessoa para exhibir la multiplicidad de su quehacer poético. Esta postura, que en líneas específicas se le denominaría como "heteronimismo», no solo evidencia e ilustra la genealogía de las diversas obras ortónimas (lo justo, lo verdadero, lo que pertenece a Pessoa) y heterónimas de Pessoa, sino que es la puerta abierta para replantear las preguntas sobre las funciones del autor y el significado de las implicancias literarias sobre dudar de la realidad de un nombre (Cf. Pizarro \& Wiesse, 2013; p. 17). 
Una lectura similar la ofrece Ani Bustamante en «Los pliegues de Pessoa», aunque desde el psicoanálisis. Dicha postura se afirma en su ponencia, sin el ánimo de ajustar el psicoanálisis en Pessoa y sí, más bien, a la inversa. La catedrática de la Complutense de Madrid se vale de la categoría lacaniana del éxtimo para entender la obra de Pessoa y, como eje transversal, al sujeto contemporáneo, y su evanescencia, a partir de la misma. Esta interpretación de la poesía de Pessoa y de sus «futuros», serán las bases para sostener cómo el lugar del inconsciente como el «otro», construye y se apropia de los sentidos más característicos de la poesía de Pessoa:

\footnotetext{
Pessoa como el poeta de los lugares intermedios encuentra la posibilidad de devenir otro. Esa otredad es justamente la del inconsciente, sin ella caemos en la pétrea muerte del psiquismo. (Bustamante, en Pizarro \& Wiesse, 2013; p. 29)
}

Finalmente, sendos artículos de Del Valle y de Wiesse, «Los futuros de Pessoa: como un umbral abierto hacia lo imposible» $\mathrm{y}$ «Heteronimia y traducción: dos futuros de Fernando Pessoa» revisan los contenidos de la poesía pessoana y los vinculan con los fundamentos ideológicos de la cultura de Occidente. Así, Del Valle cree encontrar a Platón en los versos de Pessoa cuando percibe este aspecto de la existencia vana del sujeto contemporáneo, pero capaz de imaginar, en este oscilar entre la permanencia y la trascendencia. De igual forma, bajo este rasgo, Del Valle insiste en que Pessoa se inscribe en esta actitud vital de trascender a partir de sus «papeles» o «archivos» y multiplicándose mediante sus «heterónimos», que no son más que la frágil cualidad de la identidad del ser humano y, sobre todo, que en este mundo todo es representación.

¿En qué me hace pensar Pessoa? Lo diré escuetamente: Me hace pensar en que el mundo es representación y la persona que construye esa representación es al mismo tiempo representación. Ser implica situarse, escoger. Somos el mundo que hemos creado y somos la persona que nos hemos hecho. (Del Valle, en Pizarro \& Wiesse, 2013; p. 38) 
Del mismo pensar es Wiesse, quien parte de esta fragmentación del ego pessoano. Así considera que este se ha relativizado en las fronteras del yo lírico de Pessoa y de Antonio Machado, uno de los poetas de la generación del 98 admirados por el poeta luso. Igualmente, propone que la heteronimia y la traducción de los poemas de Pessoa son una forma concreta de sus representaciones, de sus reflejos futuros. 